\title{
Optimizing Pre-service Chemistry Teachers Understanding in Reaction Related Concepts of Alipahtic Hydrocarbons
}

\author{
Woldie Belachew ${ }^{1 *}$ \\ ${ }^{1}$ Arbaminch College of Teachers Education, ETHIOPIA \\ Received 10 March 2020 - Accepted 5 June 2020
}

\begin{abstract}
The prime purpose of this investigation was to improve Pre-service Chemistry Teachers (PCTs) understanding of reaction related concepts of Aliphatic Hydrocarbons (AHCs). Participants were 12 PCTs selected from a pool of 87 second year PCTs taking Introductory Organic Chemistry course in Arbaminch college of Teachers Education, Southern Nations, Nationalities and Peoples Regional State (SNNPRS), Ethiopia. The study was carried out in 2017 G.C. The selection of partakers was made on random basis. Case study method was employed in this in-depth investigation. The study was conducted in 7 weeks duration covering all concepts of AHCs. Conventional Instructional Approach (CIA) was employed in the Comparison Group (CG) and Conceptual Change Instructional Approach (CCIA) through the use Conceptual Change Texts (CCTs) was used in the Intervention Group (IG). A semi-structured interview was used for evaluating understanding of PCTs in relation to reactions of AHCs. To analyze the interview data, a framework analysis approach was followed. Analyses showed that the PCTs in IG had improved gaining of reaction related concepts of AHCs than those in CG. Participants in the IG reflected reduced Alternative Conceptions (ACs) and more Correct Conceptions (CoCs) than those in the CG. Reduced ACs and more CoCs from analyses of detailed recordings of PCTs responses confirmed enhanced understanding of reactions of AHCs in the IG.
\end{abstract}

Keywords: organic chemistry, pre-service chemistry teachers, aliphatic hydrocarbons, conceptual change text, reactions

\section{INTRODUCTION}

Though learning is complex than perceived by scholars, the teaching-learning process is imperative to bring change in learners. Scholars and practitioners agree on this in unison. However, sometimes it becomes a simple rhetoric when understanding becomes a point of discussion in relation to learning and change on students. Perhaps, this idea could be recognized as a cumulative glimpse if empirical perspectives-which are reviewed below-are not considered. If understanding is not the center of attention of teaching-learning process run by institutes like colleges, they could be recognized simply as brick-and-mortar organizations. The nature of the learning process changes as the task of mastering a complex body of knowledge unfolds (Shuell, 1990, p. 531). Learning with understanding does indeed deserve attention in all areas of education including chemistry.
Basically learning with understanding is a synergistic product of different minds including students themselves. College students face complicatedness when they join second-year organic chemistry course (Anderson \& Bodner, 2008; Grove, Hershberger, \& Bretz, 2008). Many college instructors are willing to be inventive in their teaching, but they feel they are in short of the time and resources to make it happen (Light \& Micari, 2013).

In relation to learning problems, for instance, Anderson and Bodner's (2008) study confirmed that the problem is common to both high and low achievers of general chemistry course. Introductory Organic chemistry, in general, is complex for college level learners (O'Dwyer \& Childs, 2017). Similar to Anderson and Bodner's (2008) research, O'Dwyer and Childs's (2017) study indicated that the obscurity in introductory organic chemistry is roughly in the entire concepts

(c) 2020 by the authors; licensee Modestum. This article is an open access article distributed under the terms and conditions of the Creative Commons Attribution License (http://creativecommons.org/licenses/by/4.0/). 


\section{Contribution to the literature}

- This investigation concentrates on effectiveness of CCT-based instruction on PCTs understanding of reaction related concepts. The investigation led to findings and discussions, which in turn helped in making conclusions.

- Literature search and individual participant's response helped in the analyses process and making conclusions.

- Based on the in-depth interview positive result was obtained. Learners' alternative conceptions were reduced and their correct conceptions were improved with understanding. Thus, the result might be helpful for chemistry instruction and science education literature.

related to this course. Students taking organic chemistry have problems of visualizing molecules and reactions (Bodner \& Domin, 2000). Another study (Ahtee \& Varjola, 1998) indicated that students face reaction related difficulties not only at college level but also at secondary level. Ahtee and Varjola's (1998) study has showed that only $6 \%$ of secondary and $14 \%$ of college level students were able to describe the meaning of chemical reaction properly. Teachers are expected to go extra miles in relation to their students' understanding. To solve the problem, there are suggested strategies from literature search.

The science education community is making great efforts to get strategies for breaking the enduring deadlocks on instructional approaches in science. Unanimity on the approach to be followed by all instructors at all levels is not within reach, as there are diverse instructional approaches in education. Principally, these different approaches fall under two umbrella terms: student-centered and teacher-centered. Instructors, who are dedicated to student-centered instruction, apparently base their instructional decisions on the way students learn and what they require in classroom (Garrett, 2008). In harmony with the idea of Garrett (2008), Vachliotis, salta, Vasiliou, and Tzougraki (2011) indicated that chemistry instructors are expected to opt for instructional approaches that push students to learn meaningfully with conceptual understanding. This suggestion is in line with conceptual change approach, as conceptual change occurs when students make moves from not comprehending in what way something works to comprehending it (Mayer, 2002). Though challenging to put into practice (Nadelson, Taasoobshirazi, Heddy, Johnson, \& Jones, 2018), conceptual change approach comprises strategies such as simulations (Taslidere, 2013; Tesfaye, 2012), Peer-lead Instruction (Tien, Roth, \& Kampmeier, 2002), concept mapping (Arokoyu \& Obunwo, 2014), concept cartoons (Say \& Ozmen, 2018; Taşlidere, 2013), conceptual change texts (Sendur, 2012; Sendur \& Toprak, 2013) and flipped class rooms (Fautch, 2015).

However, challenging learner in terms of the textual materials they use becomes a key aspect to be considered (Beerenwinkel, Parchmann, \& Grasel, 2011; MamlokNaaman, Eilks, Bodner, \& Hofstein, 2018) though there is decline of use of texts (Yore, Bisanz, \& Hand, 2003). In connection to these ideas, two text versions can be used in teaching science concepts: traditional and conceptual change texts. The former one is very common and part of almost all standard references and text books in science and other disciplines. The later one is uncommon and suggested by different researchers (Armagan, Keskin, \& Akın, 2017; Sendur, 2012; Sendur \& Toprak, 2013) for its effectiveness in making learning meaningful. The use of CCTs has gradually waxed in science education today. Principally this is associated with the advantages of CCTs. Such texts demonstrate students' alternative conceptions in science concepts, explicitly emphasize that alternative conceptions are non-scientific explanations, and push students to make an attempt to disprove their alternative conceptions (Cil, 2014). Alternative conceptions are inaccurate or incomplete information that are highly challenging to change (Tippett, 2010).

Different empirical studies in science education (Armagan, Keskin, \& Akın, 2017; Sendur, 2012; Sendur \& Toprak, 2013) have indicated that CCTs are effective in ensuring students' learning with understanding. The largest fraction of introductory organic chemistry I course at college level focuses on functional groups, where aliphatic hydrocarbon related concepts such as reactions are entertained chiefly. Worthwhile understanding of such reactions related concepts of aliphatic hydrocarbons has not been adequately studied (Sendur \& Toprak, 2013; Sket \& Glazar, 2005; Vachliotis et al., 2011). Also, researcher's experience as an instructor offering the course and archival evidence of students on the study site also showed poor performance in organic chemistry course. Thus, the present study is employed to concentrate on the helpfulness of CCT on reactions related aliphatic hydrocarbon concepts.

\section{MAIN PURPOSE AND RESEARCH QUESTIONS}

The prime purpose of the study is to shed light on PCTs understanding of reaction related concepts of AHCs through the use of CCTs. In line with the above main purpose, the present study investigates the following research questions: 
1. In what ways do PCTs understand reactions related concepts of AHCs before running conceptual change through the use of CCTs and conventional instructional approaches?

2. In what ways do PCTs understand reactions related concepts of AHCs after running conceptual change through the use of CCTs and conventional instructional approaches?

3. Is there change in understanding reactions related Aliphatic Hydrocarbon (AH) concepts after running conceptual change through the use of CCTs and conventional instructional approaches?

\section{METHODOLOGY}

In this section attention is given to case study employed, context and participants, treatment, instrument used, trustworthiness and validity issue, pilot study and procedures followed.

\section{Case Study}

For description of PCTs understanding on reactions related concepts of AHCs, case study was used. This is due to the fact that case study is a rigorous study of a single unit for the purpose of understanding a larger related unit (Gerring, 2004). A single unit can be one individual, one group, one organization, or one program (Ary, Jacobs, Sorensen, \& Razavie, 2010). Case study has been used as useful qualitative research approach in chemistry related research works (Anderson \& Bodner, 2008; Sweeney, Bula, \& Cornett, 2001; Harrison \& Treagust, 2000). For example, case study was used on the use of models in understanding chemistry concepts (Harrison \& Treagust, 2000).

\section{Context and Participants}

The site of this study was Arbaminch College of Teachers Education, SNNPRS, Ethiopia. Twelve randomly selected participants were selected for this study from a convenience sample of 87 PCTs. These participants were second year chemistry students registered in Introductory Organic Chemistry I in the same college. Half of the interviewees (6 participants) were from CG and the rest six were from IG. In-depth interviews were run with these participants before and after the treatment.

\section{Treatment}

This study was conducted in 7 weeks duration covering all concepts of AHCs. The classroom instructor completed the intervention through these 7 weeks. Each week has three fifty-minute sessions. The class-hours were accompanied with a 3-hour lab session in a week. Students were taught by the same instructor throughout the intervention phase. This instructor received trainings on the implementation of conceptual change-based instruction in advance. CCTs (Appendix C) were used during classroom intervention where necessary. Reactions related concepts of AHCs were taught during usual sessions with no unique arrangement. Conventional / traditional text and CCT were employed in the present study in relation to reaction related concepts. Reactions related $\mathrm{AH}$ concepts comprised reactions of alkanes, alkenes and alkynes. Thus, CCTs were used in relation to reactions of alkanes, alkenes and alkynes. Distinctively, traditional/conventional texts which address students' alternative conceptions indirectly were used in the CG and CCTs which address students' alternative conceptions directly were used in the IG.

\section{Instrument}

To get lucid picture of PCT's understanding of reaction related concepts a semi-structured interview (Appendix A) was designed and used. Semi-structured interviews are used by researchers to discern the depictions that participants use to organize their experiences (Hatch, 2002). Such type of interview is foremost instrument for getting details provided by participants in a given qualitative study of this sort (Hatch, 2002; Solomon, 2008).

\section{Trustworthiness and Validity of the Instrument}

Trust worthiness was guaranteed based on suggestions from literature search for qualitative study of this type (Shenton, 2004). Besides, reviews made by three senior instructors in the study site determined face and content validity.

\section{Pilot Study}

Piloting was carried out carefully on the tool as well as on the approach. The tool/semi-structured interview prepared was piloted with 6 participants. The CCT approach was also piloted with 33 students. Piloting was for making sure whether students can comprehend the interview items appropriately and to know the time required for the intervention. Based on the pilot information the duration of the interview was predicted. Also, based on the pilot information classroom teaching time with CCT was predicted. Moreover, based on the piloting the grammar and wordings of some items were altered and made straightforward.

\section{Procedures of Data Collection}

The researcher prepared interview guide prior to intervention. To satisfy the objective of the study and answer the research questions, 12 PCTs were selected. From the selected participants 6 were from IG and the rest 6 were from CG. These participants were randomly selected for the interview process. Then, the participants got general orientation on individual basis. Based on this familiarization session participants consented to 
Table 1. ACs experienced by CG and IG students before intervention on Reactions of AHCs

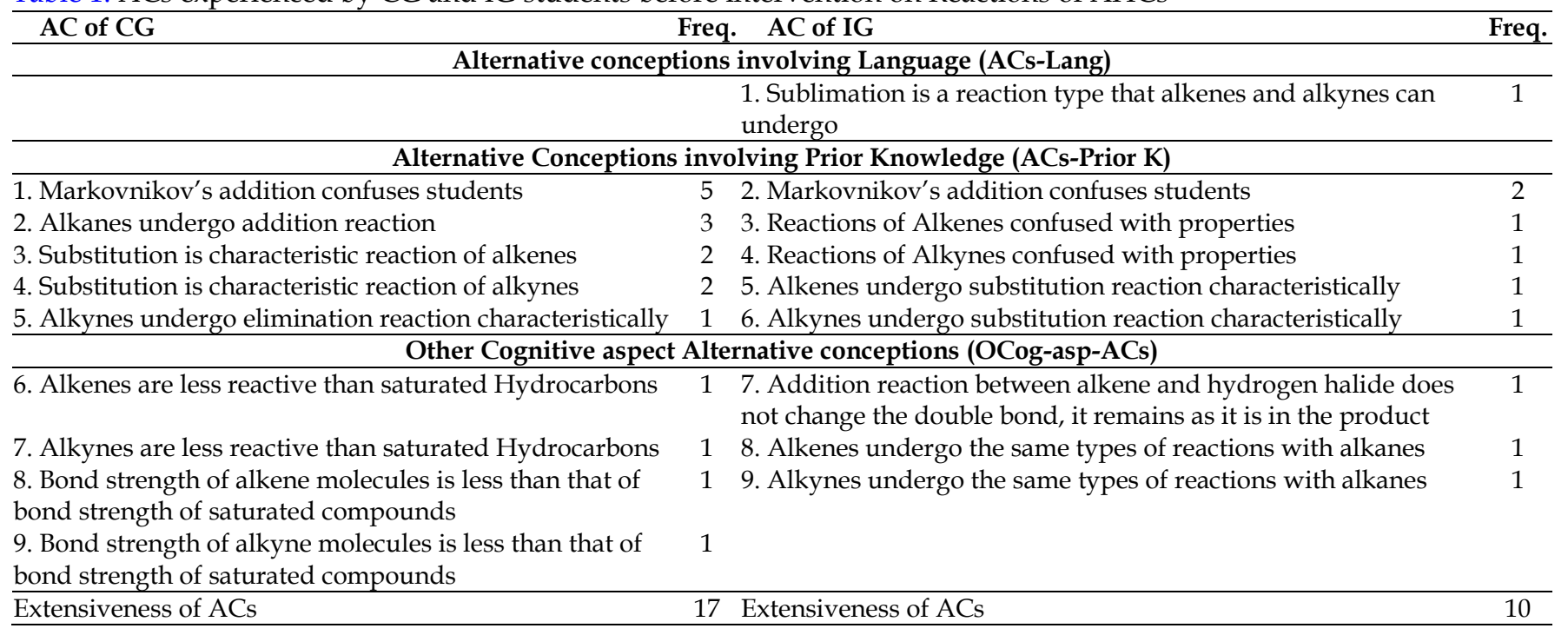

participate. Depending on the approval obtained, audio appliance was used for recording.

\section{DATA ANALYSIS}

After manual verbatim transcription beforehand, a framework analysis approach (Gale, Heath, Cameron, Rashid, \& Redwood, 2013; Rabiee, 2004; Ritchie \& Spencer, 1994) was applied to analyze data. Framework analysis involves thematic analysis and then comparisons both within and between themes. Also, semi-structured interview data analysis was through categorizing students' Alternative Conceptions (ACs), identifying CoCs, generating frequencies and extensiveness (aggregate frequencies) of concepts. Starting with the qualitative interview data, the predestined categories of ACs based on Skelly's (1993) proposals were adapted in this research. Results were made accessible using categorization of ACs and identification of CoCs based on proper science education literature (Govender \& Bekele, 2016; Osman, 2017, Sobal, 2001). Classification of ACs in to three broad categories: ACs involving language, ACs involving prior knowledge and other cognitive aspects ACs was by consulting literature (Skelly, 1993).

\section{RESULTS}

Results of the analyses were presented below in terms of Alternative Conceptions (ACs), Correct Conceptions (CoCs) and changes observed in the groups using thematized titles and tables.

\section{Prior Understanding of Reaction Related Aliphatic Hydrocarbon Concepts}

Table 1 gives a picture of ACs of Aliphatic Hydrocarbons (AHCs) in relation to reactions. In the two groups, there were 18 ACs. Nine ACs were in the Comparison Group (CG) and 9 were in the Intervention
Group (IG). From 9 ACs in the CG no AC was ACs-Lang type, 5 were ACs-prior $K$ type and 4 were OCog-AspACs. One of the 9 ACs in the IG was AC-Lang type, 5 were ACs-prior K type and 3 were OCog-Asp-ACs type. Total ACs, ACs-prior K type, and OCog-Asp-ACs were comparable. ACs-prior $\mathrm{K}$ type is dominant in both groups. From 9 ACs reported by the CG Pre-service Chemistry Teachers (PCTs), 5 were reported only once, 2 were reported twice, $1 \mathrm{AC}$ was reported three times and another 1 AC was reported five times by participants.

Again, from the nine ACs reported by IG PCTs, 1 AC was reported twice and the rest were reported only once. From the reported ACs some are reported by significant number of interviewees. For example, students in the CG opined that alkanes undergo addition reactions. Three (50\%) of the participants from the CG were with this AC before intervention. Also, the CG and IG students, were with the difficulty in understanding Markovnikov's rule. Five (83\%) of the participants from the CG and two $(33 \%)$ of the IG students were with this AC before intervention. There are other intricate areas in the IG. For instance, remarkable AC was reported from IG students in relation to substitution reaction. Two participants (33\%) from 6 who participated in the interview from IG were of opinion that substitution is a characteristic reaction for unsaturated hydrocarbons.

Table 2 shows PCTs CoCs in reactions related Aliphatic Hydrocarbon (AH) concepts. From 13 CoCs reported from the CG PCTs, 8 were reported only once, 4 were reported twice and only $1 \mathrm{CoC}$ was reported three times by participants. Again, from $11 \mathrm{CoCs}$ reported by IG PCTs, 6 were reported only once, 4 were reported twice and only 1 CoC was reported three times by participants. From the reported COCs some are explicated by majority of the participants in both groups. For example, alkanes undergo substitution reaction (50\% CG:50\% IG); alkanes undergo elimination reaction 
Table 2. PCTs CoCs in reaction related AH concepts

\begin{tabular}{lcc}
\hline \multirow{2}{*}{ Concept } & CG pre & IG pre \\
\cline { 2 - 3 } 1. Alkanes undergo substitution reaction & Frequencies & 3 \\
2. Alkanes undergo elimination reaction & 3 & 2 \\
3. Alkanes undergo dehydrogenation reaction & 1 \\
4. Alkanes undergo combustion reaction & 2 \\
5. Alkenes undergo elimination reaction & 1 \\
6. Alkenes undergo hydrogenation reaction & 2 \\
7. Alkenes undergo combustion reaction & 2 \\
8. Alkynes undergo hydrogenation reaction & 1 \\
9. Alkenes undergo hydrohalogenation reaction & 2 \\
10.Alkynes undergo hydrohalogenation reaction & 1 \\
11.Alkenes undergo hydration reaction & 1 \\
12.Alkynes undergo hydration reaction & 1 \\
13.Alkenes undergo addition reaction & 1 \\
14.Alkynes undergo addition reaction & 1 \\
15.The reaction between HBr and 2-methyl-1-butene gives CH3CH2C(CH3)(Br)CH3 in peroxide free media. & 1 \\
\hline Number of CoCs & 1 \\
Extensiveness of CoCs & 2 \\
\hline
\end{tabular}

Table 3. ACs experienced by CG and IG students after intervention on reactions of AHCs

\begin{tabular}{|c|c|c|}
\hline $\mathrm{AC}$ of $\mathrm{CG}$ & Freq. AC of IG & Freq. \\
\hline \multicolumn{3}{|c|}{ Alternative conceptions involving Language (ACs-Lang) } \\
\hline & 1) Alkenes undergo dehydration reaction & 1 \\
\hline & 2) Alkynes undergo dehydration reaction & 1 \\
\hline \multicolumn{3}{|c|}{ Alternative Conceptions involving Prior Knowledge (ACs-Prior K) } \\
\hline 1) Alkanes undergo addition reaction & 3 3) Alkanes undergo dehydration reaction & 1 \\
\hline 2) Markovnikov's addition confuses students & 5 4) Alkanes undergo hydrogenation reaction (addition reaction) & 1 \\
\hline 3) Alkenes undergo substitution reactions Characteristically & 1 5) Alkenes undergo substitution reaction characteristically & 1 \\
\hline 4) Alkynes undergo substitution reactions characteristically & 1 6) Alkynes undergo substitution reaction characteristically. & 1 \\
\hline 5) Alkynes undergo elimination reaction characteristically & 1 7) Markovnikov's rule confuses students & 1 \\
\hline 6) Alkynes undergo dehydrogenation reaction & 1 & \\
\hline \multicolumn{3}{|c|}{ Other Cognitive aspect Alternative conceptions (OCog-asp-ACs) } \\
\hline 7) Alkenes are less reactive than saturated Hydrocarbons & 1 & \\
\hline 8) Alkynes are less reactive than saturated Hydrocarbons & 1 & \\
\hline $\begin{array}{l}\text { 9) Bond strength of alkenes is less than that of bond } \\
\text { strength of saturated compounds }\end{array}$ & 1 & \\
\hline 10) Alkynes are less reactive than alkenes & 1 & \\
\hline Extensiveness of ACs & 16 Extensiveness of ACs & 7 \\
\hline
\end{tabular}

(17\%CG: 33\% IG); alkanes undergo dehydrogenation reaction (17\% CG: 33\% IG); alkanes undergo combustion reaction (33\% CG: $17 \% \mathrm{IG})$; alkynes undergo hydrogenation reaction (33\%CG: 17\% IG), alkenes undergo addition reaction (17\%CG: $33 \% \mathrm{IG}$ ) and alkynes undergo addition reaction (33\%CG: 17\% IG).

This showed that before intervention the PCTs showed low (as most COCs occurred once in CG and IG) but comparable CoCs in reaction concepts of AHCs. The interview responses of participants (both in terms of ACs and COCs) from CG and IG before intervention showed that, during the pre-test, the PCTs had difficulties in reaction related $\mathrm{AH}$ concepts with poor correct conceptions.

\section{Later Understanding of Reaction Related Aliphatic Hydrocarbon Concepts}

Table 3 gives a picture of ACs of AHCs in relation to reactions after intervention. In the two groups, there were 17 ACs. Ten ACs were in the CG and 7 were in the IG. From the 10 ACs reflected by CG Participants, 6 were
ACs-prior K type and 4 ACs were OCog-Asp-ACs type. From the 7 ACs reflected by IG Participants, 2 were ACsLang type and 5 were ACs-prior K type. OCog-Asp-ACs and ACs-Lang type were not reported in the IG and CG respectively. ACs-prior $\mathrm{K}$ type was comparable and dominant in both groups after the intervention. From ten ACs reported from the CG PCTs, 8 were reported only once, $1 \mathrm{AC}$ was reported three times and another $1 \mathrm{AC}$ was reported five times by participants. Again, all the 7 ACs reported from the IG PCTs, were reported only once. From the reported ACs, some are reported by significant number of interviewees.

For example, Markovnikov's addition confuses students in the CG. Five $(83 \%)$ of the participants from the CG were with this AC after intervention. This is also area of difficulty in the IG.

Also, the CG and IG students were with the difficulty in understanding reactions of alkanes. They opined that Alkanes undergo addition reaction. Three (50\%) of the participants from the CG were with this AC after intervention. This is also area of difficulty in the IG. 
Table 4. CoCs experienced by CG and IG students after intervention on reactions of AHCs

\begin{tabular}{|c|c|c|}
\hline \multirow{2}{*}{ Concept } & CG post & IG post \\
\hline & \multicolumn{2}{|c|}{ Frequencies } \\
\hline 1. Alkanes undergo substitution reaction & 4 & 4 \\
\hline 2. Alkanes undergo elimination reaction & 4 & 4 \\
\hline 3. Alkanes undergo combustion reaction & 3 & 5 \\
\hline 4. During combustion alkanes react with oxygen or air & 1 & 1 \\
\hline 5. During combustion alkanes can form carbon dioxide and water & & 2 \\
\hline 6. Alkenes undergo elimination reaction & & 1 \\
\hline 7. Alkenes undergo hydrogenation reaction & 1 & \\
\hline 8. Alkynes undergo hydrogenation reaction & 1 & 1 \\
\hline 9. Alkenes undergo hydrohalogenation reaction & 1 & 1 \\
\hline 10.Alkenes undergo halogenation reaction & 2 & 1 \\
\hline 11.Alkynes undergo hydrohalogenation reaction & 1 & 1 \\
\hline 12.Alkynes undergo halogenation reaction & 2 & 1 \\
\hline 13.Alkenes undergo hydration reaction & 1 & 1 \\
\hline 14.Alkynes undergo hydration reaction & 1 & 1 \\
\hline 15.Alkenes undergo addition reaction & 2 & 4 \\
\hline 16.Alkynes undergo addition reaction & 2 & 4 \\
\hline 17.The reaction between $\mathrm{HBr}$ and 2-methyl-1-butene gives $\mathrm{CH} 3 \mathrm{CH} 2 \mathrm{C}(\mathrm{CH} 3)(\mathrm{Br}) \mathrm{CH} 3$ in peroxide free media. & 1 & 5 \\
\hline Number of CoCs & 15 & 16 \\
\hline Extensiveness CoCs & 27 & 37 \\
\hline
\end{tabular}

Table 4 shows PCTs CoCs in reactions related AHCs after intervention. From fifteen $\mathrm{CoCs}$ reported by the CG PCTs, 8 were reported only once, 4 were reported twice, 1 COC was reported three times and 2 were reported four times by participants. Again, from 16 COCs reported from IG PCTs, 9 were reported only once, 1 was reported twice, no COC was reported three times, 4 were reported four times and 2 were reported five times by participants.

From the reported COCs, some are explicated by majority of the participants in both groups. For example, alkanes undergo substitution reaction (67\%CG:67\% IG); alkanes undergo elimination reaction (67\%CG: 67\% IG); alkanes undergo combustion reaction (50\%CG: $83 \% \mathrm{IG}$ ); alkenes undergo addition reaction (33\%CG: 67\% IG); alkynes undergo addition reaction (33\%CG: $67 \% \mathrm{IG}$ ) and the reaction between $\mathrm{HBr}$ and 2-methyl-1-butene gives $\mathrm{CH} 3 \mathrm{CH} 2 \mathrm{C}(\mathrm{CH} 3)(\mathrm{Br}) \mathrm{CH} 3$ in peroxide free media (17\%CG: $83 \% \mathrm{IG})$. This showed that after intervention the PCTs in the IG reflected more COCs than those in the CG in reaction concepts of AHCs. The interview responses of participants (both in terms of ACs and COCs) from CG and IG after intervention showed that, during the posttest, the PCTs in the CCIA group had reduced ACs with understanding in reaction related AHCs than those in CIA group.

\section{Changes in Understanding Reaction Related Aliphatic Hydrocarbon Concepts}

The randomly selected 12 PCTs were interviewed on questions related to reactions of AHCs before and after intervention. The interview response disclosed that, during the pretest, PCTs had comparative difficulty in describing and understanding reactions of AHCs. During the posttest, the same students showed improved understanding. But the level of understanding is much better in the case of pre-service teacher from
CCIA group. This section presents changes in reactions related AHCs understanding of PCTs. The section is divided into five thematized sub-sections: aspects related to substitution reaction; aspects related to combustion reaction; aspects related to addition reaction; aspects related to elimination reaction and reaction related other miscellaneous aspects.

\section{Aspects Related to Substitution Reaction}

Appendix $B$ gives summary of changes in understanding of Pre-service Chemistry Teachers (PCTs) in relation to substitution reaction related features of Aliphatic Hydrocarbons (AHCs). In relation to this first theme, $1 \mathrm{COC}$ and $2 \mathrm{ACs}$ were reflected from participants. Before Conventional Instructional Approach (CIA), 3 participants (C-01, C-02 and C-05) in the $\mathrm{CG}$ reflected the COC "Alkanes undergo substitution reaction". Besides, before CCIA, 3 participants (IP-01, IP02 and IP-03) in the IG reflected the same Correct Conception (COC). After intervention, 4 participants (C01, C-02, C-04 and C-05) from CIA group and 4 participants (IP-01, IP-02, IP-03 and IP-06) from CCIA group echoed the COC "Alkanes undergo substitution reaction". The change is comparable in the groups.

In relation to the same theme, the number of Alternative Conceptions (ACs) were the same in the CG and IG groups, both before and after intervention but there is difference in terms of aggregate frequencies, a change from 2 to 1 in the CG and no change in the IG (Appendix B). The ACs "Alkenes undergo substitution reaction characteristically" and "Alkynes undergo substitution reaction characteristically" were reflected by participants. The first AC was reflected by 2 of the CG participants (C-01 and C-04) before CIA. The same AC was reflected by 1 participant in the IG (IP-03) before Conceptual Change Instructional Approach (CCIA). The second $A C$ was also reflected by 2 of the CG participants 
(C-01 and C-04) before CIA. The same AC was reflected by 1 IG participant (IP-03) before CCIA. After intervention, the 2 ACs were reflected by Participants: C05 and C-06 respectively in the CG. Also, these two ACs were reflected by one Participant (IP-05) in the IG. The full account of interview data from each PCT participant in the groups (CG and IG) indicated comparable change in the groups in terms of "aspects related to substitution reaction".

\section{Aspects Related to Combustion Reaction}

Again, Appendix B gives summary of changes in understanding of PCTs in relation to "combustion reaction related features" of AHCs. In relation to this second theme, 2 COCs in both groups (both before and after intervention), $1 \mathrm{COC}$ in both groups (after intervention), 1 COC in CG (before intervention) and another $1 \mathrm{COC}$ in the IG (after intervention) were reflected from participants. For example, before CIA 1 participant (C-02) in the CG reflected the COC "Alkanes undergo combustion reaction". Furthermore, before CCIA 2 participants (IP-01 and IP-02) in the IG reflected the same COC. After intervention, 3 participants (C-01, C-02 and C-04) from CIA group and 5 participants (IP01, IP-02, IP-03, IP-04 and IP-06) from CCIA group echoed the COC "Alkanes undergo combustion reaction". There is better change in the IG in terms of this COC. Also, one participant from CG (C-03) reflected the $\mathrm{COC}$ "During combustion alkanes react with oxygen or air" after the intervention. The same COC was reflected by 1 participant from IG (IP-04). After intervention, 2 IG participants (IP-03 and IP-04) reflected the COC "During combustion alkanes can form carbon dioxide and water". This COC was not echoed by CG participants. The full account of interview data from each PCT participant in the groups (CG and IG) indicated better change in the CCIA group in terms of "aspects related to combustion reaction".

\section{Aspects Related to Addition Reaction}

Appendix B gives summary of changes in understanding of PCTs in relation to "addition reaction related features" of AHCs. In relation to this third theme, different COC and ACs were reflected from participants. For example, before CIA, 1 participant (C-02) in the CG reflected the COC "Alkenes undergo addition reaction". Moreover, before CCIA, 2 participants (IP-02 and IP-04) in the IG reflected the same COC. After intervention, 2 participants (C-01 and C-02) from CIA group and 4 participants (IP-01, IP-02, IP-04 and IP-05) from CCIA group echoed the COC "Alkenes undergo addition reaction". Besides, before CIA, 2 participants (C-02 and $\mathrm{C}-03)$ in the CG reflected the COC "Alkynes undergo addition reaction". Before CCIA, 1 participant (IP-04) in the IG reflected the same COC. After intervention, 2 participants (C-01 and C-02) from CIA group and 4 participants (IP-01, IP-02, IP-04 and IP-05) from CCIA group echoed the COC "Alkynes undergo addition reaction". What is more, before CIA, no participant in the CG and 2 participants (IP-01 and IP-02) in the IG reflected the $\mathrm{COC}$ "The reaction between $\mathrm{HBr}$ and 2methyl-1-butene gives $\mathrm{CH} 3 \mathrm{CH} 2 \mathrm{C}(\mathrm{CH} 3)(\mathrm{Br}) \mathrm{CH} 3$ in peroxide free media". After intervention, 1 participant (C-02) from CIA group and 5 participants (IP-01, IP-03, IP-04, IP-05 and IP-06) from CCIA group echoed the $\mathrm{COC}$ "The reaction between $\mathrm{HBr}$ and 2-methyl-1-butene gives $\mathrm{CH} 3 \mathrm{CH} 2 \mathrm{C}(\mathrm{CH} 3)(\mathrm{Br}) \mathrm{CH} 3$ in peroxide free media". These confirm the change is much better in the CCIA group.

In relation to the same theme, the number of ACs were the same in the CG and IG groups, both before and after intervention but there is difference. For instance, before CIA, Markovnikov's addition confuses 4 participants (C-01, C-02, C-04 and C-05) in the CG. After intervention, the number of participants with the same COC in the CG increased to 5 (C-01, C-03, C-04, C-05 and C-06). Before and after CCIA, in the IG Markovnikov's addition confused 2 Participants (IP-03 and IP-05) and 1 participant (IP-02) respectively. Also, before CIA, 3 participants (C-01, C-04 and C-06) in the CG had the AC "Alkanes undergo addition reaction characteristically". After intervention, the number of participants in the CG remained the same (C-03, C-04 and C-06) in terms of the same AC. Before and after CCIA, in the IG the AC "Alkanes undergo addition reaction characteristically" was reflected by no participant and 1 (IP-04) respectively. The full account of interview data from each PCT participant in the groups (CG and IG) indicated better change in the IG in terms of "aspects related to addition reaction".

\section{Aspects Related to Elimination Reaction}

Appendix B gives summary of changes in understanding of PCTs in relation to "elimination reaction related features" of AHCs. In relation to this fourth theme, 3 COC and different ACs were reflected from participants. Before CIA, 1 participant (C-02) in the CG reflected the COCs "Alkanes undergo elimination reaction". Besides, before CCIA, 2 participants (IP-01 and IP-02) in the IG reflected the same COC. After intervention, 4 participants (C-01, C-02, C-04 and C-05) from CIA group and 4 participants (IP-01, IP-02, IP-03 and IP-06) from CCIA group echoed the COC "Alkanes undergo elimination reaction". Moreover, before CIA, 2 participants (C-01 and C-02) in the CG reflected the COCs "Alkenes undergo elimination reaction". Also, before CCIA, 1 participant (IP-01) in the IG reflected the same COC. After intervention, 1 participant (IP-05) from CCIA group echoed the COC "Alkanes undergo elimination reaction". After CIA, no participant in the CG reflected the same COC. One participant (IP-03) reflected the $\mathrm{COC}$ "Alkanes undergo dehydrogenation reaction", before CCIA. 
Table 5. Summary of ACs and extensiveness in relation to reaction related concepts of AHCs

\begin{tabular}{cccccccc}
\hline Area of Focus & Group & AC-pre & AC-post & AC-Gain or CC & Ext-pre & Ext-post & Ext-Gain or CC \\
\hline \multirow{2}{*}{ Reactions of AHCs } & CG & 9 & 10 & -1 & 17 & 16 & +1 \\
& IG & 9 & 7 & +2 & 10 & 7 & +3 \\
\hline
\end{tabular}

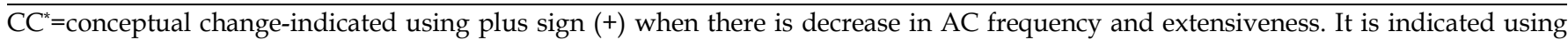
minus sign (-) when there is increase in AC freq. and ext.

In relation to the same theme, the number of $\mathrm{ACs}$ in the $C G$, were 1 and 2 before and after intervention. Before intervention, 1 participant (C-01) reflected the AC "Alkynes undergo elimination reaction characteristically". After intervention, the ACs were: "Alkynes undergo elimination reaction characteristically" and "Alkynes undergo dehydrogenation reaction". These ACs were reflected by only 1 CG Participant (C-04). In the IG, the ACs "Alkenes undergo dehydration reaction", "Alkynes undergo dehydration reaction" and "Alkanes undergo dehydration reaction" were reflected by Participants IP05, IP-03 and IP-06 respectively. The full account of interview data from each PCT participant in the groups (CG and IG) indicated that in terms of ACs the CG made better change but in terms COC the change is inconclusive.

\section{Reaction Related Other Miscellaneous Aspects}

Appendix B gives summary of changes in understanding of PCTs in relation to "reaction related other miscellaneous aspects" of AHCs. In relation to this fifth theme, no COC and several ACs were reflected from participants. The ACs of IG remained the same (4 ACs) both before and after intervention but the IG members reflected only five ACs before intervention (Appendix B). The 4 ACs reflected by CG before intervention were "Alkenes are less reactive than saturated Hydrocarbons", "Alkynes are less reactive than saturated Hydrocarbons", "Bond strength of alkene molecules is less than that of bond strength of saturated compounds" and "Bond strength of alkyne molecules is less than that of bond strength of saturated compounds". Surprisingly, these ACs were reflected by 1 Participant (C-03). After CIA, the first 3 ACs remained intact but another AC cropped up in the CG. This AC was "Alkynes are less reactive than alkenes". After intervention, except the second $\mathrm{AC}$, the others were reflected by 1 participant (C-03). The second AC was reflected by participant C-04. The 5 ACs reflected by IG before CCIA were "Sublimation is a reaction type that alkenes and alkynes can undergo (state change confused with reactions)", "Reactions of Alkenes confused with properties", "Reactions of Alkynes confused with properties", "Alkenes undergo the same types of reactions with alkanes" and "Alkenes undergo the same types of reactions with alkanes". The second and third ACs were reported by Participant IP-06 and the rest were reflected by participant IP-01. No AC was reported in the IG after the intervention. This shows there is better change in the
IG as no ACs was reported after CCIA in terms of this theme.

Overall, the interview responses obtained from the PCTs indicate that these respondents had COCs and ACs about the reactions of AHCs. In three reactions related themes (aspects related to combustion reaction; aspects related to addition reaction and reaction related other miscellaneous aspects), CCIA group made meaningful change. However, the changes are comparable and inconclusive in terms of aspects related to substitution reaction and aspects related to elimination reaction respectively. When considered holistically, the IG made better changes. This may lead us to the inference that the pre-service teachers in treatment/IG had better understanding than those in the CG in reactions related concepts of AHCs.

Table 5 shows that prior to intervention, the CG participants experienced 9 ACs but after intervention/they/CIA participants experienced 10, which shows there is no improvement in understanding reactions related AHCs. Also, the same table depicts that the extensiveness of the same group participants. Extensiveness of ACs shows improvement as the participants AC extensivenesses were 17 before intervention and 16 after intervention.

Prior to intervention, the IG participants experienced 9 ACs but after intervention/they/CCIA participants experienced 7 , which shows there is improvement in understanding reactions related AHCs. Also, the same table depicts that the extensiveness of the IG participants was with improvement. Extensiveness of ACs was 10 before intervention and 7 after CCIA. There is improvement in the IG both in terms of number of ACs and extensiveness proving the superiority of CCIA in relation to reactions of AHCs. In terms of $\mathrm{AC}$ extensiveness, there is improvement in the $\mathrm{CG}$ but the improvement is larger in the IG.

Table 6 shows that prior to intervention, the CG participants experienced 13 COCs in total but after intervention/they/CIA participants experienced 15 which shows, there is improvement in understanding $\mathrm{AH}$ concepts. Also, the same table depicts that the extensiveness of the same group participants: 19 before CIA and 27 after CIA. Extensiveness of COCs showed improvement of 8 in the group.

Prior to intervention, the IG participants experienced 11 COCs but after intervention they experienced 16 COCs, which shows there is improvement in understanding $\mathrm{AH}$ concepts. Also, the same table depicts that the extensiveness of the IG participants with 
Table 6. Summary of CoCs of groups in Reactions of AHCs

\begin{tabular}{ccccccccc}
\hline Area of Focus & Group & COC-pre & COC-post & COC-Gain & Ext-COC pre & Ext-COC post & Ext- Gain \\
\hline \multirow{2}{*}{ Reactions of AHCs } & CG & 13 & 15 & +2 & 19 & 27 & +8 \\
& IG & 11 & 16 & +5 & 17 & 37 & +20 \\
& & & & &
\end{tabular}

much improvement: 17 before CCIA and 37 after CCIA. Extensiveness of COCs showed improvement of 20, which is much higher than the CIA group value. There is much better improvement in the IG both in terms of number of ACs and COCs. The interview responses of participants (both in terms of ACs and COCs) from CG and IG after intervention showed that, during the posttest, the PCTs in the CCIA group had reduced ACs with understanding in reactions of AHCs than those in CIA group.

\section{DISCUSSION}

Alternative Conceptions (ACs) and Correct Conceptions (CoCs) of Aliphatic Hydrocarbons (AHCs) in relation to reactions were reported in the findings of this study. Conceptual Change Texts (CCTs) which deal with ACs explicitly helped learners in the Intervention Group (IG). The groups vary in terms of reaction related concepts after intervention. For instance, after intervention, the Comparison Group (CG) participants experienced more ACs than the number of ACs before Conventional Instructional Approach (CIA); however, the IG experienced less ACs after Conceptual Change Instructional Approach (CCIA). Extensiveness (aggregate frequency) in terms of ACs increased to a much larger extent in the CG compared to the increase in IG. After intervention, the CG and IG participants experienced more CoCs than the number of CoCs before CIA and CCIA respectively. Also, extensiveness in terms of CoCs increased in both groups but to a much larger extent in the CG compared to the increase in IG. After the treatment the ACs decreased on the side of CCIA participants indicating enhanced level of understanding. After intervention, the CG and IG participants experienced more CoCs than the number of CoCs before CIA and CCIA but the improvement in terms of CoCs is much better in the IG. The interview responses obtained from the PCTs indicate that these respondents had ACs on reaction of aliphatic hydrocarbons in the groups. Scientifically acceptable ideas were reflected during the interview by these participants too. The findings of this particular study concur with the findings of other study (Bilgin \& Geban, 2006; Calik, Kolomuc, \& Karagolge, 2010; Ebru \& Geban, 2012; Tastan, Yalcinkaya, \& Boz, 2008; Widarti, Marfuah, \& Parlan, 2019). For instance, in resonance related concepts of organic chemistry I course using multiple representations-based learning, Widarti, Marfuah, and Parlan (2019) found that students in IG were with greater understanding in these concepts than those in CG. Also, Tastan et al.'s (2008) finding indicated that students' understanding and achievement in conceptual change text users group in concepts of energy of chemical reactions enhanced meaningfully than those in traditional instruction group.

\section{CONCLUSION}

Developing students understanding is one of the most essential goals of chemistry education. This includes identifying students' prior knowledge before intervention. Moreover, after intervention, identifying students' knowledge helps in judging the effectiveness of the intervention. Actually, the participants of this study offered existing substantiation that presence of instruction always does not mean learning is taking place meaningfully. All participants struggled with the introductory level reaction related aliphatic hydrocarbon concepts during the treatment. However, it could be said that, being exposed to conceptual change instructional approach means learning is more evocative. Learning resources that result from instructors' exhaustive involvement, such as Conceptual Change Texts (CCTs) in this study, have added potential to be implemented effectively in today's school related settings. The results of the study revealed that the preservice chemistry teachers understanding improved in the group where the CCTs were used. The change observed in the Intervention Group (IG) carried great weight than the change in the Comparison Group (CG). Analyses showed that the IG/CCIA group understood reaction related concepts better than the CG/CIA group. That is, the PCTs in CCIA group had improved understanding in these concepts. Conceptual understanding of the PCTs taught using CCTs was better compared to those in CG. In this study, markedly important result was obtained in the IG showing the preeminence of CCIA over CIA.

\section{REFERENCES}

Ahtee, M., \& Varjola, I. (1998). Students' understanding of chemical reaction. International Journal of Science Education, 20(3), 305-316. https:/ / doi.org/10.1080/ 0950069980200304

Anderson, T. L., \& Bodner, G.M. (2008). What can we do about 'Parker'? A case study of a good student who didn't 'get' organic chemistry. Chemistry Education Research and Practice, 9, 93-101. https://doi.org/ 10.1039/B806223B

Armagan, F. O., Keskin, M. O., \& Akın, B. S. (2017). Effectiveness of conceptual change texts: A meta analysis. European Journal of Science and Mathematics Education, 5(4), 343-354.

Ary, D., Jacobs, L.C., Sorensen, C., \& Razavie, A. (2010). Introduction to research in education ( $\left.8^{\text {th }} E d.\right)$. Australia: Wadsworth, Cengage Learning. 
Beerenwinkel, A., Parchmann, I., \& Grasel, C. (2011). Conceptual change texts in chemistry teaching: A study on the particle model of matter. International Journal of Science and Mathematics Education, 9, 12351259. https:/ / doi.org/10.1007/s10763-010-9257-9

Bilgin, I., \& Geban, O. (2006) The effect of cooperative learning approach based on conceptual change condition on students' understanding of chemical equilibrium concepts. Journal of Science Education and Technology, 15(1), 31-46. https://doi.org/ $10.1007 /$ s10956-006-0354-Z

Bodner, G. M., \& Domin, D. S. (2000). Mental models: The role of representations in problem solving in chemistry. Uni. Chem. Edu., 4, 24-29.

Calik, M., Ali Kolomuc, A., \& Karagolge, Z. (2010). The effect of conceptual change pedagogy on students' conceptions of rate of reaction. Journal of Science Education and Technology, 19(5), 422-433. https: / / doi.org/10.1007/s10956-010-9208-9

Cil, E. (2014). Teaching nature of science through conceptual change approach: Conceptual change texts and concept cartoons. Journal of Baltic Science Education, 13(3),339-350.

Ebru, K., \& Geban, O. (2012). Facilitating conceptual change in rate of reaction concepts using conceptual change oriented instruction. Education $\mathcal{E}$ Science, 37(163), 216-225.

Fautch, J. M. (2015). The flipped classroom for teaching organic chemistry in small classes: Is it effective? Chem. Educ. Res. Pract. (16), 179-186. https:/ / doi.org/10.1039/C4RP00230J

Garrett, T. (2008). Student-centered and teacher-centered classroom management: A Case study of three elementary teachers. Journal of Classroom Interaction, 43(1), 34-47.

Gerring, J. (2004). What is a case study and what is it good for? The American Political Science Review, 98(2), 341-354. https://doi.org/10.1017/S0003055 404001182

Grove, N. P., Hershberger, J. W., \& Bretz, S. L. (2008). Impact of a spiral organic curriculum on student attrition and learning. Chemistry Education Research and Practice, 9, 157-162. https://doi.org/10.1039/ B806232N

Harrison, A. G., \& Treagust, D. F. (2000). Learning about Atoms, Molecules, and Chemical Bonds: A Case Study of Multiple-Model Use in Grade 11 Chemistry.Sci.Educ., 84(3), 352-381. https:/ / doi.org /10.1002/(SICI)1098-237X(200005)84:3<352::AIDSCE3>3.0.CO;2-J

Light, G., \& Micari, M. (2013). Making scientists: Six principles for effective college teaching. Cambridge: Harvard University Press. https://doi.org/ 10.2307/j.ctvjghtn6
Mamlok-Naaman, R., Eilks, I., Bodner, G., \& Hofstein, A. (2018). Professional Development of Chemistry Teachers Theory and Practice. England and Wales: Royal Society of Chemistry.

Mayer, R. E. (2002). Understanding Conceptual Change: A Commentary. In M. Limon and L. Mason (Eds.), Reconsidering conceptual change: Issues in theory and practice (pp. 101-114). New York: Kluwer Academic. https://doi.org/10.1007/0-306-476371_5

Nadelson, L. S., Taasoobshirazi, G., Heddy, B. C., Johnson, M., \& Jones, S. (2018). Conceptual change in science teaching and learning: Introducing the dynamic model of conceptual change. International Journal of Educational Psychology, 7(2), 151-195. https:/ / doi.org/10.17583/ijep.2018.3349

O'Dwyer, A., \& Childs, P. E. (2017). Who says organic chemistry is difficult? Exploring perspectives and perceptions. EURASIA Journal of Mathematics Science and Technology Education, 13(7), 3599-3620. https://doi.org/10.12973/eurasia.2017.00748a

Say, F. S., \& Ozmen, H. (2018). Effectiveness of Concept Cartoons on 7th Grade Students' Understanding of "the Structure and Properties of Matter". Journal of Turkish Science Education, 15(1),1-24

Sendur, G., \& Toprak, M. (2013). The Role of Conceptual Change Texts to Improve Students' Understanding of Alkenes. Chem. Edu. Res. Prac., 14, 431-449. https:// doi.org/10.1039/C3RP00019B

Sendur, G. (2012). Prospective science teachers' misconceptions in organic chemistry: The case of alkenes. Journal of Turkish Science Education, 9(3), 186-190.

Shuell, T. J. (1990). Phases of meaningful learning. Review of Educational Research, 60(4), 531-547. https:/ / doi.org/10.3102/00346543060004531

Sket, B., \& Glazar, S. A. (2005). Using concept maps in teaching organic chemical reactions. Acta Chim. Slov., 52, 471-477.

Sweeney, A. E., Bula, O. A., \& Cornett, J. W. (2001). The role of personal practice theories in the professional development of a beginning high school chemistry teacher. Journal of Research in Science Teaching, 30(4), 408-441. https:/ / doi.org/10.1002/tea.1012

Taslidere, E. (2013). Effect of conceptual change-oriented instruction on students' conceptual understanding and decreasing their misconceptions in DC electric circuits. Creative Education, 4(4), 273-282. https:/ / doi.org/10.4236/ce.2013.44041

Tastan, O., Yalcinkaya, E., \& Boz, Y. (2008). Effectiveness of conceptual change text-oriented instruction on students' understanding of energy in chemical reactions. Journal of Science Education and Technology, 17, 444-453. https://doi.org/10.1007/ s10956-008-9113-7 
Hailegebreal, T. D. (2012). Effects of pedagogy-basedtechnology on chemistry students' performance in higher education institutions of Ethiopia: A case study of Debre Berhan University. Unpublished PhD Dissertation, University of South Africa. Retrieved from http:/ / hdl.handle.net/10500/10351

Tien, L. T., Roth, V., \& Kampmeier, J. A. (2002). Implementation of a peer-led team learning instructional approach in an undergraduate organic chemistry course. Journal of Research in Science Teaching, 39(7), 606-632. https://doi.org/ $10.1002 /$ tea. 10038

Tippett, C. D. (2010). Refutation text in science education: A review of two decades of research. International Journal of Science and Mathematics Education, 8(6), 951-970. https://doi.org/10.1007/ s10763-010-9203-x
Vachliotis, T., Salta, K., Vasiliou, P., \& Tzougraki, C. (2011). Exploring novel tools for assessing high school students' meaningful understanding of organic reactions. Journal of Chemical Education, 88(3), 337-345. https:/ / doi.org/10.1021/ed9000415

Widarti, H. R., Marfuah, S., \& Parlan, P. (2019). Improving chemistry prospective teacher's conceptual understanding of resonance using multiple representations. Advances in Social Science, Education and Humanities Research, 253, 208-213. https://doi.org/10.2991/aes-18.2019.49

Yore, L. D., Bisanz, G. L., \& Hand, B. M. (2003). Examining the literacy component of science literacy: 25 years of language and science research. International Journal of Science Education, 25(6), 689725. https:/ / doi.org/10.1080/09500690305018 


\section{APPENDIX A}

\section{Semi-structured Interview protocol for Reaction related AHCs}

Thank you for agreeing to be interviewed. I am doing this interview to explore students' understanding of aliphatic hydro carbon concepts in relation to the article entitled: “OPTIMIZING PRE-SERVICE CHEMISTRY TEACHERS UNDERSTANDING IN REACTION RELATED CONCEPTS OF ALIPAHTIC HYDROCARBONS". The data obtained from this interview will be transcribed and used for academic purpose. Everything you say will be strictly confidential. Your name will not be included in the written transcript of this study. We will stick to reaction related AH concepts. This interview will take 10-20 minutes (approximately). If you would prefer not to answer any of the questions during the interview just let me know and we will move on to the next question. It is possible to stop at any time during the interview if you want not to give ideas. Is this good idea?

\section{Informed Consent}

Do you have any question before we start? Do you agree to participate in this interview?

\section{Interviewee Background Data}

\begin{tabular}{l} 
Code of interviewee \\
\hline Agex \\
\hline Department \\
Year \\
\hline Date of the interview
\end{tabular}

\section{Interview Items}

1. What are the characteristic reactions of Alkanes? Explain with examples.

2. What are the characteristic reactions of Alkenes and Alkynes? Explain.

a. Given the structure below, predict which of the compounds shown would be the major product of the reaction of $\mathrm{HBr}$ with 2-methyl-1-butene in peroxide free media. Why?<smiles>CCC(Br)CC</smiles>

(A)<smiles>CCC(C)(C)Br</smiles>

(B)<smiles>CC(C)C(C)C</smiles>

(C)<smiles>CCCC(C)Br</smiles>

(D)<smiles>CC(C)(C)CBr</smiles>

(E) 
APPENDIX B

\section{Changes in Understanding of Reactions of AHCs}

\begin{tabular}{|c|c|c|c|c|c|c|c|c|c|}
\hline \multirow[t]{3}{*}{ Theme } & \multirow[t]{3}{*}{ Idea manifested } & \multicolumn{4}{|c|}{ CG Participants } & \multicolumn{4}{|c|}{ IG Participants } \\
\hline & & \multicolumn{2}{|c|}{$\mathrm{CC}$} & \multicolumn{2}{|c|}{$\mathrm{AC}$} & \multicolumn{2}{|c|}{$\mathrm{CC}$} & \multicolumn{2}{|c|}{$\mathrm{AC}$} \\
\hline & & Pre & post & Pre & post & Pre & post & Pre & post \\
\hline \multirow{3}{*}{$\begin{array}{l}\text { Aspects } \\
\text { related to } \\
\text { substitution } \\
\text { reaction }\end{array}$} & Alkanes undergo substitution reaction-3 & $\begin{array}{l}\text { C-01, C-02, } \\
\text { C-05 }\end{array}$ & $\begin{array}{c}\text { C-01, C- } \\
02, \mathrm{C}-04 \\
\mathrm{C}-05\end{array}$ & - & - & $\begin{array}{l}\text { IP-01, IP- } \\
02, \text { IP-03 }\end{array}$ & $\begin{array}{l}\text { IP-01, IP-02, } \\
\text { IP-03, IP-06 }\end{array}$ & - & - \\
\hline & $\begin{array}{l}\text { Alkenes undergo substitution reaction } \\
\text { characteristically }\end{array}$ & - & - & $\begin{array}{l}\text { C-01, } \\
\text { C-04 }\end{array}$ & C-05 & - & - & $\begin{array}{c}\mathrm{IP}- \\
03\end{array}$ & IP-05 \\
\hline & $\begin{array}{l}\text { Alkynes undergo substitution reaction } \\
\text { characteristically }\end{array}$ & - & - & $\begin{array}{l}\text { C-01, } \\
\text { C-04 }\end{array}$ & C-06 & - & - & $\begin{array}{l}\text { IP- } \\
03\end{array}$ & IP-05 \\
\hline \multirow{4}{*}{$\begin{array}{l}\text { Aspects } \\
\text { related to } \\
\text { combustion } \\
\text { reaction }\end{array}$} & Alkanes undergo combustion reaction & C-02 & $\begin{array}{l}\text { C-01, C- } \\
02, \mathrm{C}-04\end{array}$ & - & - & $\begin{array}{l}\text { IP-01, IP- } \\
02\end{array}$ & $\begin{array}{c}\text { IP-01, IP-02, } \\
\text { IP-03, IP-04, } \\
\text { IP-06 }\end{array}$ & - & - \\
\hline & Alkenes undergo combustion reaction & C-02 & - & - & - & - & - & - & - \\
\hline & $\begin{array}{l}\text { During combustion alkanes react with } \\
\text { oxygen or air }\end{array}$ & - & C-03 & - & - & - & IP-04 & - & - \\
\hline & $\begin{array}{l}\text { During combustion alkanes can form } \\
\text { carbon dioxide and water }\end{array}$ & - & - & - & - & - & IP-03, IP-04 & - & - \\
\hline \multirow{8}{*}{$\begin{array}{l}\text { Aspects } \\
\text { related to } \\
\text { addition } \\
\text { reaction }\end{array}$} & Alkynes undergo hydrogenation reaction & C-04, C-05 & - & - & - & IP-06 & - & - & - \\
\hline & Alkenes undergo hydration reaction & C-05 & - & - & - & IP-05 & - & - & - \\
\hline & Alkynes undergo hydration reaction & C-05 & - & - & - & IP-06 & - & - & - \\
\hline & Alkenes undergo addition reaction & C-02 & C-01, C-02 & - & - & IP-2, IP-04 & $\begin{array}{l}\text { IP-01, IP-02, } \\
\text { IP-04, IP-05 }\end{array}$ & - & - \\
\hline & Alkynes undergo addition reaction & C-02, C-03 & C-01, C-02 & - & - & IP-04 & $\begin{array}{l}\text { IP-01, IP-02, } \\
\text { IP-04, IP-05 }\end{array}$ & - & - \\
\hline & Alkenes undergo hydrogenation reaction & C-04, C-05 & C-03 & - & - & - & - & - & - \\
\hline & $\begin{array}{l}\text { Alkenes undergo hydrohalogenation } \\
\text { reaction }\end{array}$ & C-05 & C-04 & - & - & - & IP-04 & - & - \\
\hline & $\begin{array}{l}\text { Alkynes undergo hydrohalogenation } \\
\text { reaction }\end{array}$ & C-05 & C-06 & - & - & - & IP-06 & - & - \\
\hline
\end{tabular}


APPENDIX B (continued)

\section{Changes in Understanding of Reactions of AHCs}

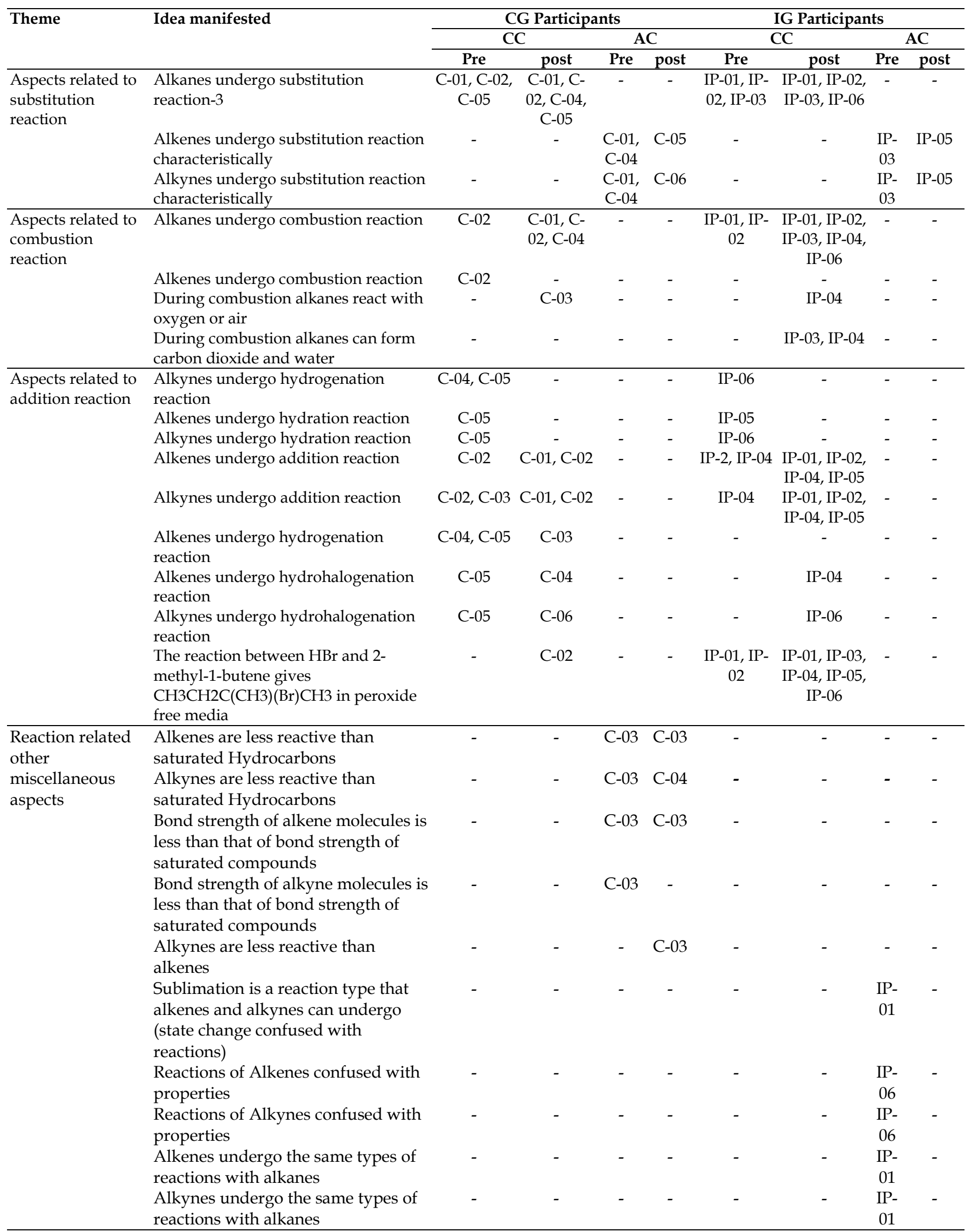




\section{APPENDIX C}

\section{Sample Conceptual Change Text on Reactions of AHCs}

What is the name of the compound formed when the following compounds react? Why? Explain.

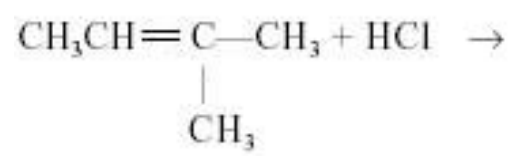

(I) 2-chloro-2-methylbutane

(II) 2-chloro-3-methylbutane

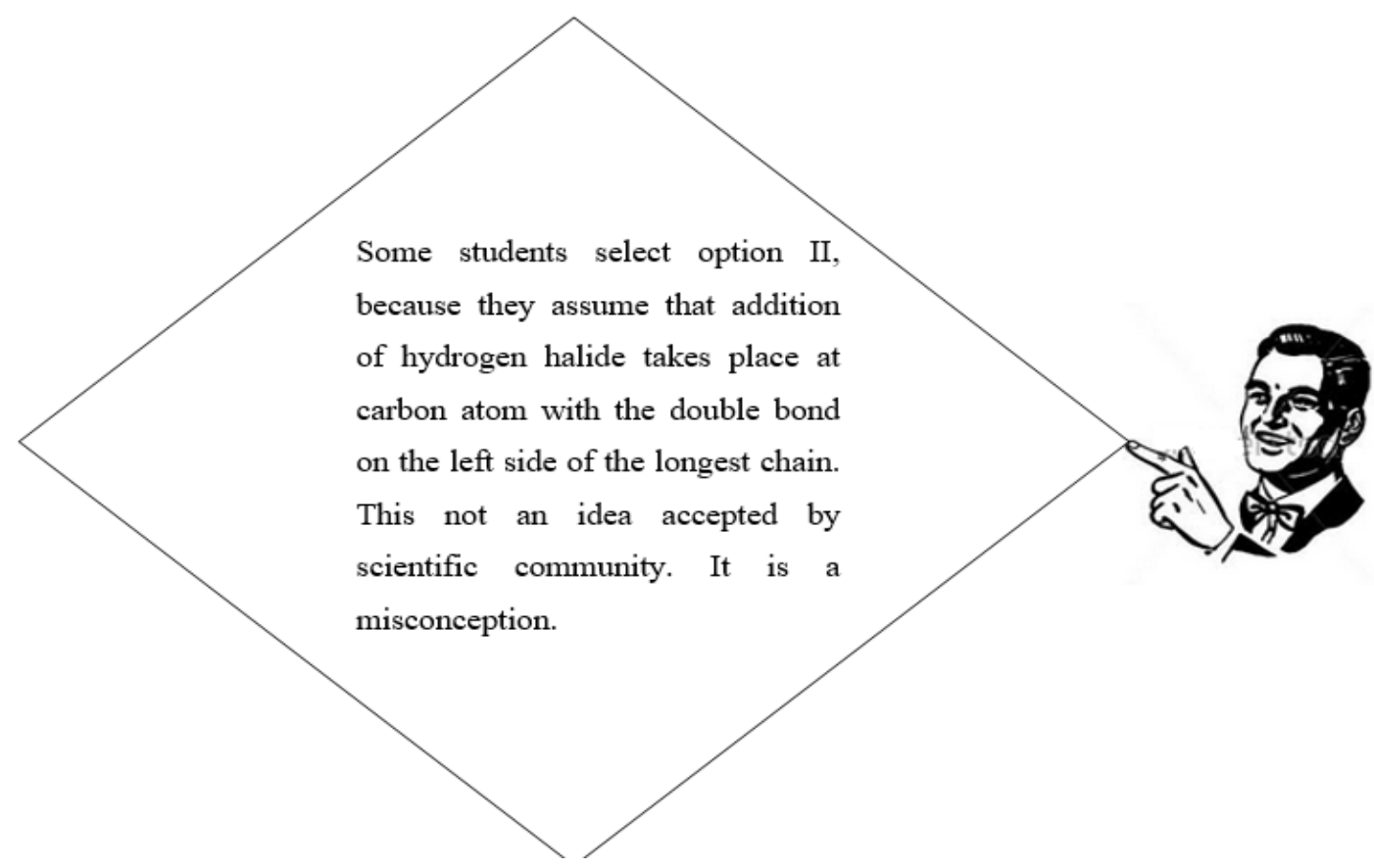

How do we predict the addition product of multiple bond or double bond containing hydrocarbons?

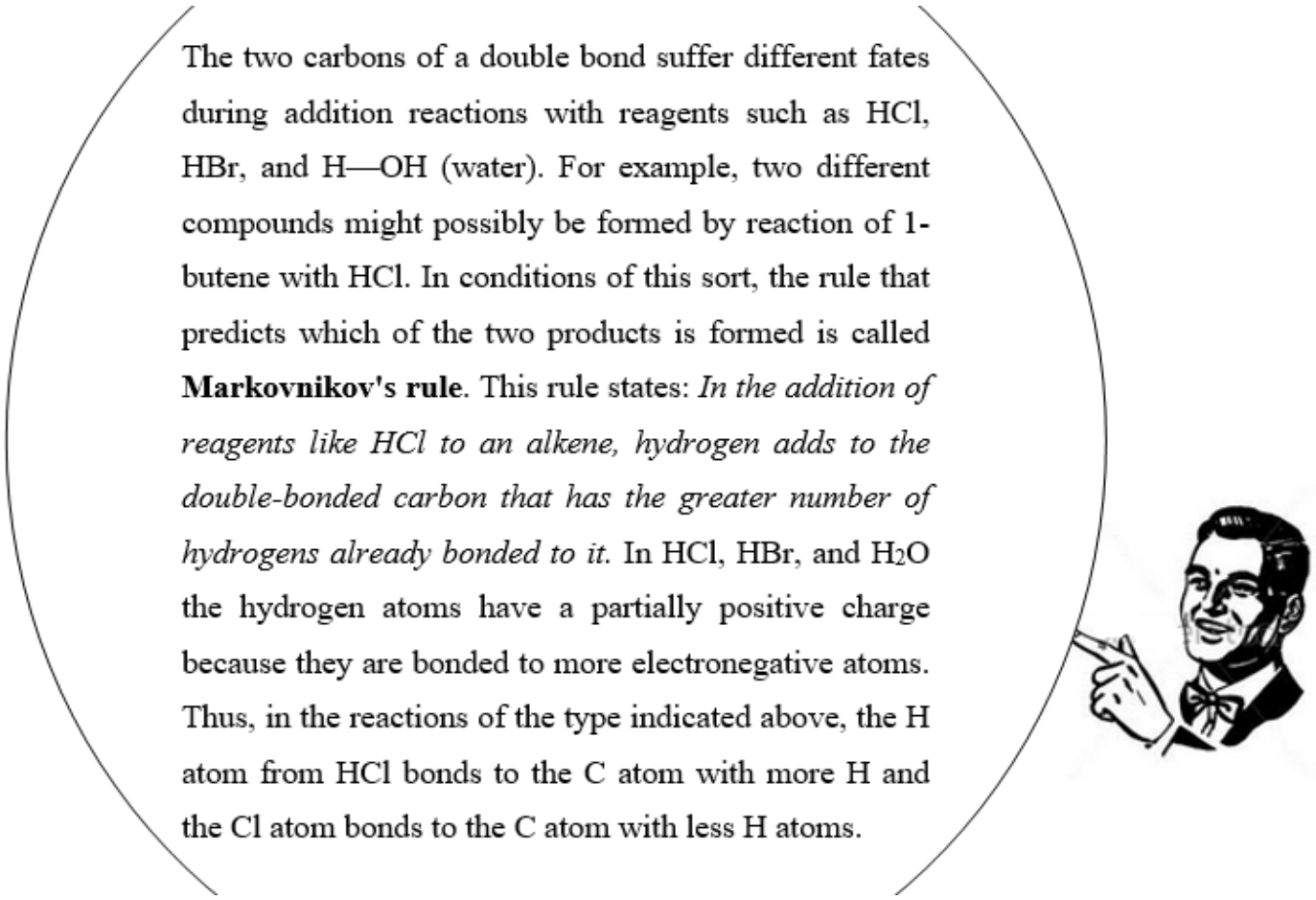

Thus, the name of the compound formed is 2-chloro-2-methylbutane 
Examples:

1) $\mathrm{CH}_{3} \mathrm{CH}_{2} \mathrm{CH}=\mathrm{CH}_{2}+\mathrm{HCl} \rightarrow \mathrm{CH}_{3} \mathrm{CH}_{2} \mathrm{CHCl}-\mathrm{CH}_{3}$

2)<smiles>C=C(C)C</smiles>

3)

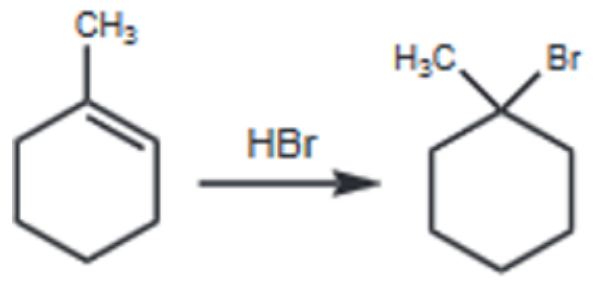

http://www.ejmste.com 